Relations industrielles

Industrial Relations

\title{
L'Église et le capitalisme
}

\section{Comte della Torre}

Volume 4, numéro 9, mai 1949

URI : https://id.erudit.org/iderudit/1023968ar

DOI : https://doi.org/10.7202/1023968ar

Aller au sommaire du numéro

Éditeur(s)

Département des relations industrielles de l’Université Laval

ISSN

0034-379X (imprimé)

1703-8138 (numérique)

Découvrir la revue

Citer cet article

Torre, C. d. (1949). L'Église et le capitalisme. Relations industrielles / Industrial Relations, 4(9), 90-90. https://doi.org/10.7202/1023968ar
Résumé de l'article

On a beaucoup cité c'est temps-ci un article sur l'Eglise et le capitalisme, paru dans, "Osservatore Ronumo ", sous la signature de son directeur, le comte della Torre. Nous en donnons ici de tres larges extraits.
Tous droits réservés (C) Département des relations industrielles de l’Université Laval, 1949
Ce document est protégé par la loi sur le droit d'auteur. L’utilisation des services d'Érudit (y compris la reproduction) est assujettie à sa politique d'utilisation que vous pouvez consulter en ligne.

https://apropos.erudit.org/fr/usagers/politique-dutilisation/ 


\section{L'EGLISE ET LE CAPITALISME}

On a beaucoup cité cest lemps-ci un article sur l'Eglise et le capitalisme, paru dans $l$ «Osservatore Romano », sous la signature de son directeur, le comte della Torre. Nous en donnons ici de très larges extraits. ${ }^{1}$

Après avoir rappelé l'enseignement des papes. de Léon XIII à Pie XII, le directeur de l'«Osservatore Romano » poursuit:

\section{Capitalisme et christianisme}

'Tels sont l'esprit, la doctrine et la conduite de i'Eglise face au capitalisme qui, pour le christianisme est essentiellement un péché contre le droit naturel analogue à celui qui, dans le domaine di «croissez et multipliez-vous», consiste à limiter les naissances. Le capitalisme capte et monopolise la richesse, c'est-à-dire qu'il empêche que croisse le nombre de ceux qui en profitent, que se multiplie sa distribution et que s'opère la péréquation des biens, s'opposant ainsi à la Providence de Dieu, qui a créé les biens de la terre pour tous les hommes, posant par là un principe, une promesse, une loi absolument inviolable. Loi qui, si elle ne contredit pas le droit de propriété, comme I’a si bien souligné Léon XIII, indique que le communisme, en tant que système économique, à l'exclusion de sa philosophie, n'est pas autant que le capitalisme contre la nature du christianisme. Le communisme le devient aussi lorsqu'il professe une philosophie athée. Mais c'est là une incrustation idéologique qui vient corrompre l'origine et le contenu économique de sa pensée. Le capitalisme n'a pas de pensée, il n'est pas victime d'un athéisme idéologique, il est athée par lui-même et du fait même de sa structure. Son Dieu est l'argent.

Imaginer ou dénoncer l'Eglise comme alliée du capitalisme et l'enchaîner à son char de triomphe est une autre de ces accusations qui sont de pures calomnies.

\section{Ni alliée, ni complice}

Il en est aussi qui parlent de «complicité nécessaire entre l'Eglise et le capitalisme, dans une société où les libertés morales et religieuses, qui ne portent pas ombrage au capitalisme, conservent le droit de subsister dans la vie des Etats, que le capitalisme domine ou contrôle. Mais cela est une autre erreur. Car l'Eglise, ce sont précisément les pontifes qui ne cessent de dénoncer pareil état de choses, cette tyrannie d'argent contre laquelle se révèle impuissante la force sociale et politique.

Pie XI, en diagnostiquant le mal capitaliste, avait déjà rappelé que l'idée que la guerre est une conséquence du capitalisme et de sa politique n'était pas une théorie découverte et propagée par le communisme. Mais le propre de l'Eglise est de découvrir la cause du désarroi des esprits lorsque, de l'ètude de l'esclavage de l'Etat, on en vient à étudier les raisons de la prostration sociale.

A ce propos, Pie XII déclarait, dans son message de 1941: "Nous voyons, d'un côté, d'immenses richesses dominer l'économie privée et publique et même toute l'activité civile; et, d'autre part, linnombrable multitude de ceux qui, hors du souci de leur propre sécurité matérielle, n’ont plus aucun souci des véritables valeurs spirituelles, se ferment à tout parti politique, et se font les esclaves de quiconque leur promet, en quelque manière, le pain et la tranquillité. Et l'expérience a démontré quelles tyrannies, dans ces conditions, l'humanité d'aujourd'hui est encore capable d'engendrer. »

(1) Témoignage Chrétien - Paris, vendredi 3 juin 1949.

\section{VERS LA LIBRE ENTREPRISE}

\section{RÉFORMES DE STRUCTURE dans l'entreprise}

Un livre de 210 pages de MM. P.-E. Bolté, Marcel Clément et Gérard Dion 